Original Research Paper

\title{
Dominant Multidrug-Resistant Bacteria in Five Biggest Hospitals in Asir Region from March to June 2018
}

\author{
Mohammed Almaghrabi \\ Department of Microbiology and Clinical Parasitology, College of Medicine, King Khalid University, Saudi Arabia
}

\section{Article history}

Received: 10-12-2020

Revised: 18-02-2021

Accepted: 08-03-2021

Email: malmaghrabi@kku.edu.sa

\begin{abstract}
There is a rapid increase in the emergence of multidrug resistance which consider as one of the public health threats in all over the world. MDR was defined as acquired non-susceptibility to at least one agent in three or more antimicrobial categories. The present study aims to determine the dominant multi-drug resistant bacteria in the five biggest hospitals in Asir region, Saudi Arabia. Antibioticresistant isolates were collected from five hospitals of the Asir region between 30 March and 1 June 2018. The isolates were tentatively identified by routine bench tests and confirmed by using VITEK ${ }^{\circ} 2$ Compact. The antibiotic susceptibility of these isolates was identified using the latest instrument. Routine bench tests and VITEK ${ }^{\circledR} 2$ Compact identified 12 dominant bacterial strains including; Staphylococcus aureus, Staphylococcus haemolytics, Staphylococcus epidermidis, Streptococcus pneumoniae, Enterococcus faecium, Enterobacter cloacae, Acinetobacter baumannii, Proteus mirabilis, Klebsiella pneumoniae, Pseudomonas aeruginosa, Escherichia coli and Proteus penneri. P. aeruginosa was majorly found in all selected hospitals. Antibiotic susceptibility in this study showed that the highest resistance rate was against penicillins (21.6\%) and cephalosporin (20.1\%). These isolates have shown resistance to fluoroquinolones $(13.8 \%)$ and aminoglycosides (10.1\%). The study concluded that the resistance rate was high against $\beta$ lactam antibiotics, particularly cephalosporins, which is considered as a new threat in hospitals.
\end{abstract}

Keywords: Antibiotic, Dominant, Resistance Rate, Saudi Arabia, Susceptibility

\section{Introduction}

Antimicrobial Resistance (AMR) is one of the most serious problems which has been exacerbated globally (Schwaber and Carmeli, 2007). The association between AMR reduced clinical efficacy and increased mortality and treatment cost has been identified in various studies (Stratchounski et al., 2005; Herati and Blumberg, 2012; Gudiol and Carratalà, 2014). Bacteria are highly influential in developing resistance during some medical procedures especially those based on antibiotic approaches such as organ transplantation, chemotherapy and surgeries (Stratchounski et al., 2005). Some bacterial strains have been functional in elevating the influence of antibiotics; although the use of antibiotics has a potential impact on bacterial treatment. MethicillinResistant $S$. aureus (MRSA) is one of such examples that causes resistance against antibiotics such as; methicillin, macrolides, aminoglycoside, tetracycline, chloramphenicol and vancomycin (De Lencastre et al., 2007). There is an increased emergence of multi-drug resistant gram-negative strains such as; $P$. aeruginosa, $A$. baumannii (Nikaido, 2009).

A widespread of the multi-drug resistant organisms have been observed in the ecology outside hospitals (Rafei et al., 2015). Contaminated animal products (Huijbers et al., 2014), dust (Blaak et al., 2015), air (von Salviati et al., 2015), animal manure (Laube et al., 2014) are some direct and indirect transmitters of the major transmitters of multi-drug resistant organisms. The dissemination of multi-drug resistant organisms is due to the reasons which include; misuse or overuse of antibiotics in animals and humans, continuous population mobilization and absence of infection control measures (Dandachi et al., 2019). 
A systematic literature review of multidrug-resistant in Gram-Negative Bacilli (GNB) revealed a substantial increase in the rate of carbapenem-resistant GNB in Saudi Arabia in the last decade. Besides, there is an increased prevalence of Extended-Spectrum BetaLactamase (ESBL) producing isolates from Saudi Arabia, where some institutes had 29 and 65\% ESBL rates among $E$. coli and $K$. pneumoniae, respectively. Moreover, there is an association between increasing rates and reported outbreaks, with mortality ranging between 11 and 40\% (Zowawi, 2016).

The emergence of multidrug resistance is increasing dramatically; although the majority of $P$. aeruginosa isolates remain susceptible to carbapenems, quinolones and aminoglycosides in most reports in different parts of Saudi Arabia. Ceftazidime, ciprofloxacin and aminoglycosides remain active against $A$. baumannii isolates (Yezli et al., 2014); however, a high rate of multidrug-resistant $A$. baumannii emerged as an important health problem with a prevalence rate of $69 \%$ in the south region of Saudi Arabia (Almaghrabi et al., 2018). In a similar context, the present study aims to determine the most dominant multidrug-resistant bacteria in Asir region. This is the first study to report the dominant multidrug-resistant bacteria in Asir region.

\section{Materials and Methods}

\section{Ethical Approval}

The study was approved by the Research Ethics committee, college of medicine, King Khalid University, Abha, Kingdom of Saudi Arabia.

\section{Bacterial Isolates}

Clinical isolates $(n=300)$ were collected from five different hospitals including Abha Maternity and Children Hospital (AMCH) $(n=50)$, King Fahad Armed and Forces Hospital (KFAFH) $(\mathrm{n}=70)$, Asir Central Hospital $(\mathrm{ACH})(\mathrm{n}=80)$, Ahad Rufaidah Hospital $(\mathrm{ARH})(\mathrm{n}=50)$ and Khamis Mushayt Hospital $(\mathrm{KMH})$ $(n=50)$ in Asir region in the south of Saudi Arabia. The study was conducted between 30 March and 1 June 2018. All these strains were initially isolated and identified in the hospital laboratories and then were sent to the Department of Microbiology, College of Medicine, King Khalid University for further study.

\section{Media and Reagents}

Two culture media were used in this experiment: Blood agar (Oxoid Ltd, Basingstoke and Hampshire, United Kingdom) and MacConkey agar (Oxoid). MacConkey agar was used as selective and differential media; while blood agar was used for other processes such as sensitivity test. Biochemical reagents such as catalase, coagulase, oxidase and indole were used as initial identification tests.

\section{Bacterial Identification and Purification}

All clinical isolates were cultured on both blood and MacConkey agar and then tested for grams staining. Several biochemical tests were undertaken to confirm that all these isolates belonged to specific bacteria. Identities of all strains were done using the automated VITEK ${ }^{\circledR} 2$ Compact (Biomeraux) by following manufacturer instructions.

\section{Antibiotic Susceptibility for Isolated Bacteria}

All isolates were tested for antibiotic susceptibility using the VITEK® 2 Compact automated system. All samples were cultured on blood agar and then a suspension was made for every isolate. A liquid suspension of all isolates was loaded on VITEK® 2 Compact system and left overnight to get the results. The next day, the identification and antibiotic susceptibility of loaded samples were obtained.

VITEK® 2 Compact system was used for authenticating names of all bacterial species as described by the manufacturer (bioMérieux Inc., Durham, NC 27712, USA). The VITEK® 2 Compact card contains 64 wells, which hold different fluorescent biochemical assays. Out of the 64, 20 are carbohydrate assimilation; whereas, 4 are for phosphatase, urea, nitrate and actidione tests. The VITEK® 2 Compact controlled card automatically including filling, sealing and transferring the cards into the linked incubator $\left(35^{\circ} \mathrm{C}\right)$. Each output report is decoded according to a particular algorithmic system. The acquired results were compared to the Identification of Gram-Negative Bacteria (ID-GN) databank. Descriptive statistics (mean $\pm \mathrm{SD}$, percentages) were used to describe the antibiotic resistance.

\section{Results and Discussion}

\section{Identification of Tested Isolates}

The characteristics of isolated colonies were obtained using cultivation on Blood and MacConkey agar, with the application of the biochemical test. The identification of these isolates revealed 12 bacterial strains; $S$. aureus, S. haemolytics, S. epidermidis, S. pneumoniae, E. faecium, E. cloacae, A. baumannii, P. mirabilis, $K$. pneumoniae, $P$. aeruginosa, E. coli and $P$. penneri.

$P$. aeruginosa and $K$. pneumoniae were found to be a multidrug-resistant pathogen in almost all hospitals $(K$. pneumoniae was not isolated from $\mathrm{ACH}$ ). Whereas, multidrug-resistant strains of $A$. baumannii was isolated from three hospitals; AMCH, ARH and KMH. E. coli was isolated from AMCH and KFAFH. P. mirabilis, $S$. epidermidis, S. haemolytics and E. faecium dominate 
multidrug-resistant in ACH. E. cloacae and P. penneri were frequently isolated from $\mathrm{ARH}$ and $\mathrm{KMH}$, respectively (Fig. 1).

\section{Antibiotic Susceptibility of Isolated Bacteria}

Antibiotic susceptibility showed that most of the isolates were considered as different serotypes even they share the same genus. For example, $P$. aeruginosa strains were isolated from all hospitals; however, they showed different resistant activity to used antibiotics. These isolates of $P$. aeruginosa strains were all resistant to $\beta$ lactam antibiotics. While the isolates from KFAFH were resistant to aminoglycoside (tobramycin), isolates from $\mathrm{KMH}$ were resistant to trimethoprim and isolates from $\mathrm{ACH}$ were resistant to fluoroquinolone (levofloxacillin) and glycylcycline (minocycline). The same observation was obtained for other bacterial isolates like $K$. pneumonia, which showed resistance to aminoglycoside (tobramycin, gentamycin), fluoroquinolone (levofloxacin) and carbapenem (meropenem and ertapenem) in different hospitals (Table 1).

Multidrug resistance is a real threat to different countries as it negatively influences the quality of life
(Stratchounski et al., 2005; Herati and Blumberg, 2012; Gudiol and Carratalà, 2014). MRSA, VRSA and $A$. baumannii were reported in Asir region (Yezli et al., 2014; Almaghrabi et al., 2018). In the present study, multidrug-resistant and extensively resistant bacterial strains were isolated and identified from the five biggest hospitals in the southern region of Saudi Arabia. The study showed that there were twelve common multidrugresistant bacterial strains in this part of the country, which were frequently identified in all selected hospitals; $P$. aeruginosa was dominant amongst all. Findings further indicated that isolated gram-negative bacteria were resistant to ampicillin; whereas all gram-positive isolates were resistant to erythromycin.

The resistance rate of these isolates was significantly high against $\beta$ lactam antibiotics particularly penicillins and cephalosporins (21.6 and 20.1\% respectively). Both gram-positive and gram-negative isolates were resistant to fluoroquinolones with a resistance rate of $13.8 \%$. While, the resistance rate of Fluoroquinolones against $E$. cloacae, A. baumannii, P. mirabilis, E. coli and $P$. penneri was $13.8 \%$, considering all the isolates.

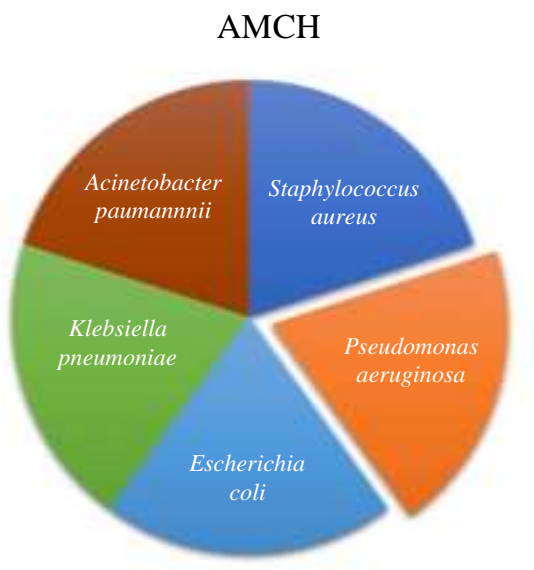

$\mathrm{KMH}$

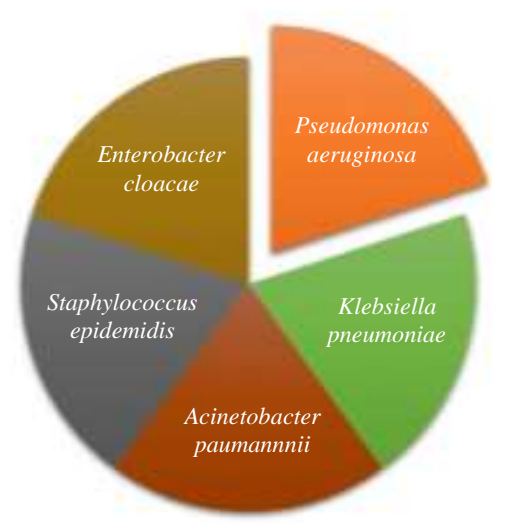

$\mathrm{ACH}$

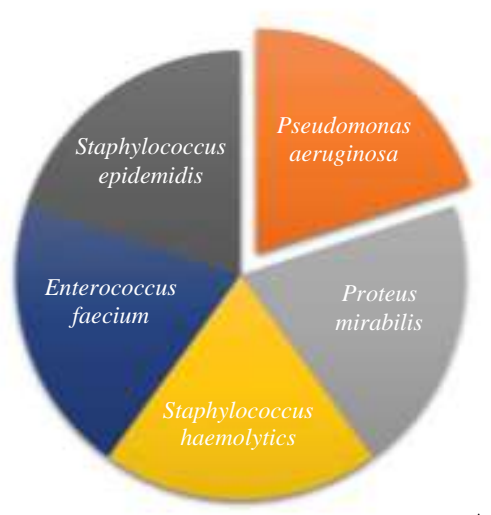

ARH

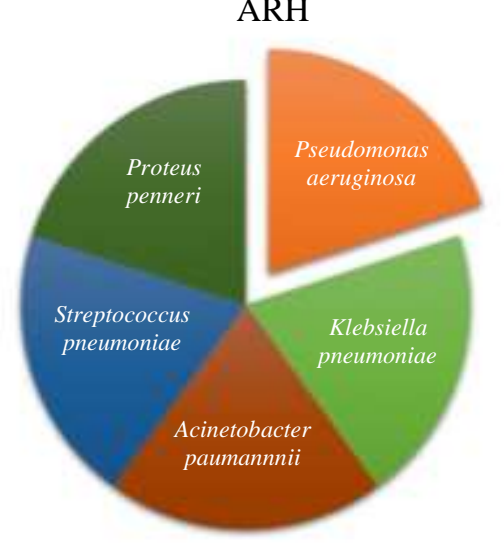

KFAFH

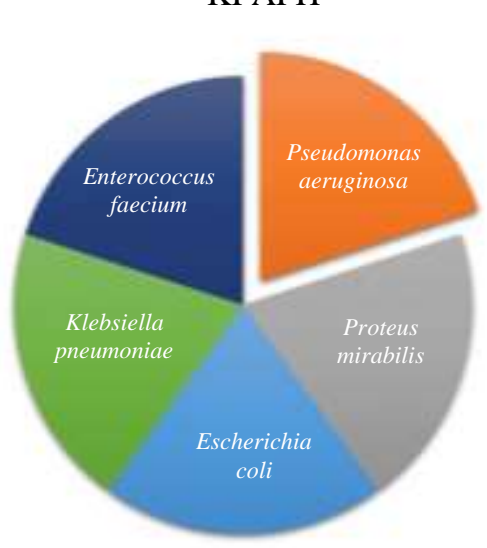

Fig. 1: Distribution of multidrug-resistant bacteria among the biggest five hospitals in Asir region. It shows the distribution of MDR bacteria among these hospitals 
Table 1: Resistance rate of antibiotics for isolates from the five biggest hospitals, Abha, Saudi Arabia, during the period from March to June 2018

\begin{tabular}{|c|c|}
\hline Antibiotics & Resistance $(\%)$ \\
\hline Penicillins & 21.6 \\
\hline Penicillin G & 2.5 \\
\hline Mezlocillin & 3.8 \\
\hline Amoxicillin & 1.3 \\
\hline Ampicillin & 8.9 \\
\hline Oxacillin & 1.3 \\
\hline Piperacillin & 2.5 \\
\hline Ticarcillin & 1.3 \\
\hline Monobactam & 2.5 \\
\hline Aztreonam & 2.5 \\
\hline Cephalosporin & 20.1 \\
\hline Cefalotin & 2.5 \\
\hline Cefepime & 2.5 \\
\hline Cefotaxime & 3.8 \\
\hline Cefoxitin & 3.8 \\
\hline Ceftriaxone & 2.5 \\
\hline Cefuroxime & 2.5 \\
\hline Ceftazidime & 2.5 \\
\hline Aminoglycoside & 10.1 \\
\hline Gentamycin & 6.3 \\
\hline Amikacin & 2.5 \\
\hline Tobramycin & 1.3 \\
\hline Trimethoprim & 3.0 \\
\hline Mupirocin & 1.3 \\
\hline Carbapnem & 8.9 \\
\hline Imipenem & 3.8 \\
\hline Ertapenem & 1.3 \\
\hline Meropenem & 3.8 \\
\hline Aminoglycoside & 10.1 \\
\hline Gentamycin & 6.3 \\
\hline Amikacin & 2.5 \\
\hline Tobramycin & 1.3 \\
\hline Macrolids & 6.3 \\
\hline Erythromycin & 6.3 \\
\hline Chloramphenicol & 1.0 \\
\hline Fluoroquinolons & 13.8 \\
\hline Ciprofloxacin & 6.3 \\
\hline Levofloxacin & 5.0 \\
\hline Moxifloxacin & 2.5 \\
\hline Tetracyclines and Glycylcyclines & 3.9 \\
\hline Tetracycline & 1.3 \\
\hline Minocycline & 1.3 \\
\hline Tigecycline & 1.3 \\
\hline Fusidic acid & 2.5 \\
\hline Lincosamides & 5.0 \\
\hline Clindamycin & 5.0 \\
\hline
\end{tabular}

\section{Conclusion}

The study concluded that there is a need of applying a developed controlling system to minimize the distribution of these isolates among different hospitals. The spread of bacteria might be due to the hospital environment, duration of hospital admission, intercurrent illness, patient comorbidities, ICU complexities and use of antimicrobial agents. Routine surveillance to track resistant bacteria is recommended to assist quality control programs in different hospitals. Increasing resistance of multi-drug organisms is documented in the majority of regions of Saudi Arabia that is a real challenge for local health authorities. However, future studies need to focus on the northern region concerning the comprehensive surveillance programs for understanding the origins and extent of different multidrug resistance organisms. The knowledge about multidrug resistance organisms also has to be improved by developing a local antibiogram database that is coupled with nationwide antimicrobial stewardship and infection prevention program.

\section{Acknowledgment}

The author is thankful to all the associated personnel, who contributed in this study by any means.

\section{Ethics}

This article is original and contains unpublished material. The corresponding author confirms that all of the other authors have read and approved the manuscript and no ethical issues involved.

\section{References}

Almaghrabi, M. K., Joseph, M. R., Assiry, M. M., \& Hamid, M. E. (2018). Multidrug-resistant Acinetobacter baumannii: An emerging health threat in aseer region, Kingdom of Saudi Arabia. Canadian Journal of Infectious Diseases and Medical Microbiology, 2018. https://doi.org/10.1155/2018/9182747

Blaak, H., van Hoek, A. H., Hamidjaja, R. A., van der Plaats, R. Q., Kerkhof-de Heer, L., de Roda Husman, A. M., \& Schets, F. M. (2015). Distribution, numbers and diversity of ESBLproducing E. coli in the poultry farm environment. PloS one, 10(8), e0135402. https://doi.org/10.1371/journal.pone.0135402

Dandachi, I., Chaddad, A., Hanna, J., Matta, J., \& Daoud, Z. (2019). Understanding the epidemiology of multi-drug resistant gram-negative bacilli in the Middle East using a one health approach. Frontiers in microbiology, 10, 1941. https://doi.org/10.3389/fmicb.2019.01941

De Lencastre, H., Oliveira, D., \& Tomasz, A. (2007). Antibiotic resistant Staphylococcus aureus: a paradigm of adaptive power. Current opinion in microbiology, 10(5), 428-435. https://doi.org/10.1016/j.mib.2007.08.003

Gudiol, C., \& Carratalà, J. (2014). Antibiotic resistance in cancer patients. Expert review of anti-infective therapy, 12(8), 1003-1016. https://doi.org/10.1586/14787210.2014.920253 
Herati, R. S., \& Blumberg, E. A. (2012). Losing ground: multidrug-resistant bacteria in solid-organ transplantation. Current opinion in infectious diseases, 25(4), 445-449. https://doi.org/10.1097/QCO.0b013e328354f192

Huijbers, P. M., Graat, E. A., Haenen, A. P., van Santen, M. G., van Essen-Zandbergen, A., Mevius, D. J., ... \& van Hoek, A. H. (2014). Extended-spectrum and AmpC $\beta$-lactamase-producing Escherichia coli in broilers and people living and/or working on broiler farms: prevalence, risk factors and molecular characteristics. Journal of Antimicrobial Chemotherapy, 69(10), 2669-2675. https://doi.org/10.1093/jac/dku178

Laube, H., Friese, A., Von Salviati, C., Guerra, B., \& Rösler, U. (2014). Transmission of ESBL/AmpCproducing Escherichia coli from broiler chicken farms to surrounding areas. Veterinary microbiology, 172(3-4), 519-527. https://doi.org/10.1016/j.vetmic.2014.06.008

Nikaido, H. (2009). Multidrug resistance in bacteria. Annual review of biochemistry, 78, 119-146. https://doi.org/10.1146/annurev.biochem.78.082907. 145923

Rafei, R., Hamze, M., Pailhoriès, H., Eveillard, M., Marsollier, L., Joly-Guillou, M. L., ... \& Kempf, M. (2015). Extrahuman epidemiology of Acinetobacter baumannii in Lebanon. Applied and environmental microbiology, $\quad 81(7), \quad 2359-2367$. https://doi.org/10.1128/AEM.03824-14
Schwaber, M. J., \& Carmeli, Y. (2007). Mortality and delay in effective therapy associated with extendedspectrum $\quad \beta$-lactamase production in Enterobacteriaceae bacteraemia: a systematic review and meta-analysis. Journal of Antimicrobial Chemotherapy, 60(5), 913-920. https://doi.org/10.1093/jac/dkm318

Stratchounski, L. S., Taylor, E. W., Dellinger, E. P., \& Pechere, J. C. (2005). Antibiotic policies in surgery: a consensus paper. International journal of antimicrobial agents, 26(4), 312-322. https://doi.org/10.1016/j.ijantimicag.2005.07.002

von Salviati, C., Laube, H., Guerra, B., Roesler, U., \& Friese, A. (2015). Emission of ESBL/AmpCproducing Escherichia coli from pig fattening farms to surrounding areas. Veterinary microbiology, 175(1), 77-84. https://doi.org/10.1016/j.vetmic.2014.10.010

Yezli, S., Shibl, A. M., Livermore, D. M., \& Memish, Z. A. (2014). Prevalence and antimicrobial resistance among Gram-negative pathogens in Saudi Arabia. Journal of chemotherapy, 26(5), 257-272. https://doi.org/10.1179/1973947814Y.0000000185

Zowawi, H. M. (2016). Antimicrobial resistance in Saudi Arabia: An urgent call for an immediate action. Saudi medical journal, 37(9), 935. https://doi.org/10.15537/smj.2016.9.16139 